\title{
Fragmentation Genetics of
}

Vateria indica: implications for

management of forest genetic

resources of an endemic

dipterocarp

\section{Journal Article}

Author(s):

Ismail, Sascha A.; Ghazoul, J.; Ravikanth, Gudasalamani; Kushalappa, Cheppudira G.; Uma Shaanker, Ramanan; Kettle, Chris J.

Publication date:

2014-06

Permanent link:

https://doi.org/10.3929/ethz-b-000078278

Rights / license:

In Copyright - Non-Commercial Use Permitted

Originally published in:

Conservation Genetics 15(3), https://doi.org/10.1007/s10592-013-0559-7 


\title{
Fragmentation Genetics of Vateria indica: implications for management of forest genetic resources of an endemic dipterocarp
}

\author{
S. A. Ismail · J. Ghazoul • G. Ravikanth • \\ C. G. Kushalappa $\cdot$ R. Uma Shaanker • \\ C. J. Kettle
}

Received: 16 September 2013/ Accepted: 20 December 2013/Published online: 7 January 2014

(C) Springer Science+Business Media Dordrecht 2014

\begin{abstract}
Tropical agro-forest landscapes are potentially valuable reserves of forest genetic resources for forestry and restoration of degraded forests. The Dipterocarpaceae is a dominant Southeast Asian family of tree species of global significance for the tropical timber industry. Very little information exists about how effective human modified landscapes are for conserving genetic diversity in dipterocarp species. This study provides a baseline for understanding how fragmented agro-forest landscapes in India sustain forest genetic resources in an endemic dipterocarp tree. We compare genetic diversity and fine-scale
\end{abstract}

S. A. Ismail $(\bowtie) \cdot$ J. Ghazoul · C. J. Kettle

Institute of Terrestrial Ecosystems, Ecosystem Management, ETH Zürich, 8092 Zürich, Switzerland

e-mail: sascha.ismail@env.ethz.ch

URL: http://www.ecology.ethz.ch

Present Address:

S. A. Ismail

Botanischer Garten und Botanisches Museum Berlin-Dahlem, Freie Universität Berlin, Königin-Luise-Straße 6-8,

14195 Berlin, Germany

e-mail: s.ismail@bgbm.org

URL: http://www.bgbm.org

G. Ravikanth · R. Uma Shaanker

Ashoka Trust for Research in Ecology and the Environment, Royal Enclave, Srirampura, Jakkur Post, Bangalore 560064, India

C. G. Kushalappa

College of Forestry, University of Agricultural Sciences (Bangalore), Kodagu District, Ponnampet 571216, Karnataka, India

R. Uma Shaanker

Department of Crop Physiology, University of Agricultural

Sciences, GKVK Campus, Bangalore 560065, India spatial genetic structure (FSGS) in the threatened tree species Vateria indica within an isolated and a continuous forest site in the Western Ghats, South India. We place these results in the context of dipterocarps from both the Seychelles and Borneo. Parentage analysis of 694 progeny using twelve nuclear microsatellite markers is applied to estimate pollen and seed dispersal. Using a nursery trial we evaluate effects of inbreeding on growth performance. Our results show that levels of FSGS, and gene dispersal are comparable between a small isolated and a large continuous site of $V$. indica. Realized long-distance pollen flow into the isolated patch appears to help maintaining genetic diversity. The nursery experiment suggests that selection favours outbred progeny. Individuals of $V$. indica in close proximity appear less related to each other than in another highly fragmented and endangered dipterocarp species from the Seychelles, but more related than in three dipterocarp species studied in continuous forest in Borneo. We discuss the wider implications of our findings in the context of conservation and restoration of dipterocarp forest genetic resources in fragmented populations.

Keywords Agro-forest landscape - Fine scale spatial genetic structure - Forest genetic resources - Inbreeding · Pollen dispersal $\cdot$ Seed dispersal

\section{Introduction}

Tropical agricultural landscape mosaics which include significant numbers of forest trees offer great potential as centres of biodiversity outside of protected areas (Perfecto and Vandermeer 2008; Anand et al. 2010). However, these novel landscapes are generally highly fragmented with spatially disrupted tree populations and individual trees 


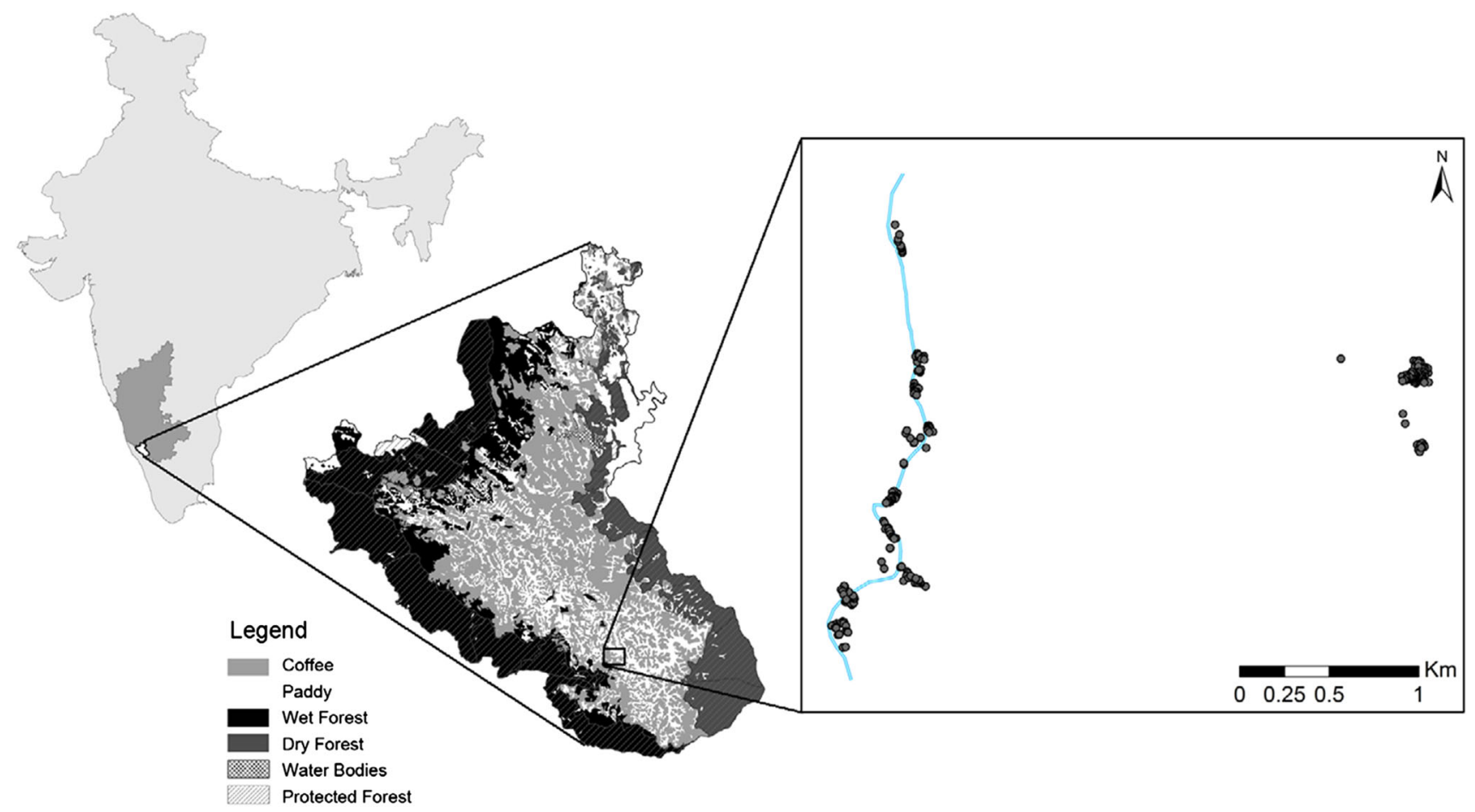

Fig. 1 Location of Kodagu district and study area within India. Kodagu district with main land use types is shown on the central map (adapted from Garcia et al. 2010). Insert map on the right shows the

that are isolated from conspecifics. The significance of such fragmentation for conservation of forest genetic resources (FGR) remains poorly resolved. Fragmentation has direct consequences for reproduction of individual species by reducing the number of reproductive individuals, altering pollen and seed dispersal patterns and affecting reproductive output (Aizen and Feinsinger 1994; Ghazoul 2005). In addition, genetic consequences including genetic drift and inbreeding (Lowe et al. 2005; Aguilar et al. 2008) are known to be important in accelerating extinction risk (Spielman et al. 2004; Frankham 2005).

The erosion of tree species diversity in tropical landscapes is likely to have considerable consequences for biodiversity at higher trophic levels through cascade effects (Manning et al. 2006). However, studies of forest fragmentation and intervening matrix quality for biodiversity in human dominated landscapes (Koh et al. 2010) rarely consider genetic biodiversity despite its fundamental importance (Laikre et al. 2010). Advancing our understanding of the potential of fragmented landscape mosaics to provide repositories of FGR is urgently required to support biodiversity conservation and forest restoration planning.

There is a burgeoning body of research demonstrating that the genetic response of tropical tree species to fragmentation is highly idiosyncratic and can show both positive (Dick 2001; White et al. 2002; Jha and Dick 2010; total study area; dots show adult Vateria indica trees with the isolated site on the right and the continuous site on the left

Ottewell et al. 2010), and negative responses (Garcia et al. 2005; Breed et al. 2012; Ismail et al. 2012). Few studies have explored these processes in one globally important family of tropical trees, the Dipterocarpaceae, which dominate the forest canopy of Southeast Asia, and account for a quarter of the global trade in tropical hardwoods (ITTO 2008).

The ultimate objective of this study is to advance our understanding of the importance of fragmented agro-forest landscapes for conserving FGR in an important dipterocarp species. Within a complex landscape mosaic we investigate the effect of spatial isolation on genetic structure and gene flow in Vateria indica, a critically endangered timber species endemic to the Western Ghats, South India (Ashton 1998). The study area is located in Kodagu district in a highly fragmented agro-forest landscape dominated by coffee plantations and paddy (Fig. 1) where $V$. indica only occurs in a single large more continuous population and a smaller isolated population.

We evaluate genetic diversity, fine-scale spatial genetic structure (FSGS), inbreeding and patterns of seed and pollen dispersal in this landscape using 12 nuclear microsatellite loci and a sample of 240 adult trees and 694 progeny to elucidate the consequences of fragmentation for the underlying FGR. We compare our findings with patterns of FSGS and direct estimates of mean pollen dispersal distances of other dipterocarp species from published data. 
In addition to investigate whether inbreeding has negative consequences on growth performance, we compare genetic diversity and relatedness in nursery-raised seedlings with wildlings (forest seedlings).

Using the above framework we address the following research questions: (1) Does a small isolated forest patch of $V$. indica retain comparable levels of genetic diversity to a larger more continuous forest patch? (2) Do patterns of gene flow and consequently genetic structure differ across life stages and between a continuous and isolated forest patch of $V$. indica. (3) What are the conservation and management options for retaining genetic diversity in fragmented $V$. indica populations? This research has relevance for the persistence of many forest tree species restricted to fragments in human dominated landscapes. More specifically, the comparison with other dipterocarp species from continuous and fragmented populations adds to the body of research on the many overexploited and highly fragmented timber tree species within this family. The Dipterocarpaceae provide an interesting family in the context of forest fragmentation genetics as they exhibit traits that are likely to make them especially vulnerable to negative genetic factors. First, strong fine-scale spatial genetic structure appears to be common in this family of trees (Kettle et al. 2011a; Harata et al. 2012). Second, if pollen mediated gene flow is restricted in fragmented habitats this may lead to increase mating among related individuals (Ismail et al. 2012). Third, limited seed dispersal potential coupled with highly recalcitrant seeds means propagules are highly unlikely to reach new sites for colonisation and forest regeneration. Management of germplasm for enrichment planting or restoration through artificial seeding or planting of dipterocarps is thus of great relevance. Finally, very little is known about the implications of fragmentation for reproduction in the dipterocarps as most published work has been conducted in continuous forest habitats (Kettle et al. 2012).

\section{Methods}

Study area and study species

The study site is located in the Western Ghats biodiversity hotspot within Kodagu district, South India (Fig. 1). Within this district we focus on three separate forest patches that contain $V$. indica. These patches are surrounded by an agricultural matrix consisting of shade coffee plantations and paddy and lie within the transition of wet evergreen forest to dry deciduous forest. Two small patches of 1.3 and 0.1 ha are separated by $320 \mathrm{~m}$ where we located 85 adult trees in total (68 trees in the larger patch, 14 trees in the smaller patch and three singleton trees in the surrounding coffee plantations). These two patches were considered as one site for analysis and the canopy is dominated by the focal species with $61 \mathrm{~V}$. indica trees per ha. A third forest patch is located $2.3 \mathrm{~km}$ west of the two small patches and represents the nearest adjacent $V$. indica forest trees. This third forest is restricted to a river-bank bordered by shade coffee plantations. Here we sampled over an area of 20 ha 155 adult trees along a $2.4 \mathrm{~km}$ stretch of river running from north to south. We considered the trees within this site as part of a single more continuous population extending along the river further towards the south but not to the north. Based on a minimum convex polygon around all the sampled trees the entire study area covered in total 492 ha.

Vateria indica is endemic to the Western Ghats and an integral species of the most western lowland dipterocarp forests dominated by $V$. indica and Dipterocarpus indicus (Pascal and Pelissier 1996). V. indica is listed as critically endangered on the 2013 IUCN Red List based on its overexploitation for its timber and its habitat loss of more than $80 \%$ (Ashton 1998). This species is considered suitable for restoration of degraded wet evergreen rain forests due to its high survival and fast growth (Rai 1990). V. indica is almost strictly biannually flowering with white fragrant flowers with c. $18 \mathrm{~mm}$ calyx width. The genus Vateria is known to be principally bee pollinated (Ashton 1988). Indeed, Apis dorsata and less frequently Apis cerana are frequently observed foraging on the flowers (Ismail pers. obs. 2009). The wingless and typically one seeded fruit ripen during peak monsoon in July and August (Murali 1997). The fruit weighs around $12.5 \mathrm{~g}$ (Murali 1997) and is expected to drop near the mother tree as there is no dispersal agent known. Because the fruits float, the species has the potential for long distance seed dispersal by water, but no studies have been conducted to explore seed viability after submergence in water.

\section{Sample collection}

For all our sample collections we defined adult trees by their diameter at breast height $(\mathrm{DBH})$ of more than $10 \mathrm{~cm}$. This threshold was chosen because we observed at this stage orthotropic branching, which indicates the transition to a mature flowering tree (Durand 1997). Wildlings were defined by their maximum height of $50 \mathrm{~cm}$.

In the small isolated patches we mapped all the adult trees to an accuracy of $5 \mathrm{~m}$ with a Garmin 60CSx handheld GPS. We collected leaf or cambium tissue from all 85 adult trees. Progeny samples were collected from the small isolated patches in the 2009 fruiting season. For this, 30 adult trees were randomly selected and 20 fresh fruits collected from the ground within 10 metres of each of these putative mothers. Half of the fruits collected were stored in silica 
gel for genetic analysis and half were used for the nursery experiment. This resulted in 300 fruit samples dissected within 1 day to obtain pure embryo tissue and 310 fruit samples (including ten fruits collected under one additional tree) planted within 2 days. These were planted into two litre polyethylene bags filled with a mixture of one part local red soil, two parts cow dung and two parts river sand and kept under a $50 \%$ shade cloth. Of the 310 fruits initially planted, 228 germinated (of which 40 were lost due to ants which nested in the seed as soon as the seed coat split) and 202 survived for 21 months. We collected leaf tissue from the surviving seedlings. To prevent local effects, such as daylight orientation and neighbour competition, the seedlings were rotated monthly within the shade house. To reduce mortality due to a caterpillar infestation we applied a single dose of insecticide uniformly across the plants. Seedling growth was measured monthly from soil surface to top of the apical meristem with an accuracy of $0.5 \mathrm{~cm}$.

In May 2012 we mapped and sampled leaf tissue of 120 wildlings. Five wildlings were sampled for leaf material each within $10 \mathrm{~m}$ of the trunk of 24 randomly selected trees in the isolated population. To maximise the probability of sampling wildlings from the 2009 fruiting event, and not the 2011 fruiting event we only sampled wildlings if their seed coat was completely absent.

In April 2010 we sampled and mapped 155 adult trees growing along $2.4 \mathrm{~km}$ of a river running from north to south and forming a continuous patch of forest. Within the first $1.6 \mathrm{~km}$ of the river we exhaustively sampled all adult $V$. indica trees. For the next $0.8 \mathrm{~km}$ the abundance of trees was too great to sample all, therefore we sampled at 200 metre intervals up to 20 individuals within a 50-m radius (see Fig. 1). All trees were sampled for cambium or leaf tissue. For the wildling sampling we collected leaf tissue from a maximum of 20 individuals within a $10-\mathrm{m}$ radius of each of six selected putative mother trees. The sampling sites for wildlings were evenly distributed along the river population with a distances between putative parent trees ranging from 250 to $500 \mathrm{~m}$ from north to south.

\section{Genotyping}

All tissue samples except the nursery samples were lyophilised with silica gel for storage prior to DNA extraction. The nursery samples were frozen at $-20{ }^{\circ} \mathrm{C}$ before processing. Genomic DNA was extracted from the tissue samples with a CTAB-method (Sambrook et al. 1989 ) in the conservation genetic laboratory at the Ashoka Trust for Ecology and the Environment (ATREE). Subsequent genotyping was conducted using 12 nuclear microsatellite markers (Vi93, Vi15, Vi16, Vi55, Vi45,
Vi13, Vi60, Vi91, Vi18, Vi78, Vat14 and Vat10) shown to be suitable for population genetic studies of $V$. indica (Ismail et al. 2013). The microsatellite loci were amplified following the PCR conditions described in Ismail et al. (2013). The amplified fragments were analysed in an ABI3730 capillary sequencer and scored relative to a LIZ 500 HD size standard in GeneMapper 3.5 (Applied Biosystems). All DNA samples from adult trees were successfully genotyped at eight or more loci. Of the DNA samples from wildlings between 98 and $99 \%$ amplified at eight or more loci. Because DNA extraction from the seed did not yield the same DNA quality as the leaf samples, only $84 \%$ (259 samples of the 310 ) of the seed DNA samples amplified at eight or more loci (See Table 1 for the overview of samples genotyped successfully at eight or more loci).

\section{Genetic analysis}

\section{Levels of genetic diversity, inbreeding and differentiation}

Deviations from Hardy-Weinberg equlibrium (HWE) and frequency of null alleles at each locus, were calculated in CERVUS 3.0.3 (Marshall et al. 1998) separately for the adult samples from the continuous population and the isolated population. For the adult populations, the wildling samples, the seed and the nursery samples we calculated the mean number of alleles $\left(\mathrm{N}_{\mathrm{a}}\right)$, the observed heterozygosity $\left(\mathrm{H}_{\mathrm{o}}\right)$ and the expected heterozygosity $\left(\mathrm{H}_{\mathrm{e}}\right)$ with GeneAlEx $6.5 b 3$ (Peakall and Smouse 2006). Additionally we estimated the inbreeding coefficient $\left(\mathrm{F}_{\mathrm{is}}\right)$, the allelic richness $\left(\mathrm{R}_{\mathrm{s}}\right)$ and the pairwise levels of differentiation $\left(\mathrm{F}_{\mathrm{st}}\right)$ with FSTAT 2.9.3.2 (Goudet 1995) using 1,000 permutations.

\section{Estimating gene flow patterns}

To directly estimate realized gene flow we applied the delta maximum-likelihood exclusion analysis to assign the two most likely parents to the juvenile samples with CERVUS 3.0 (Marshall et al. 1998; Kalinowski et al. 2007). The combined non-exclusion probability for a parent pair of our marker set was $5.3 \times 10^{-7}$. Simulations of parentage were based on the allele frequencies from all the 240 adult trees from both populations that served as candidate parents. We simulated 10,000 offspring with the following parameters: the minimum number of typed loci was set at six, the error rate of mistyped loci was set at $1 \%$ with $99.3 \%$ of the loci genotyped and allowing for selfing. The parameter settings of the parentage simulations differed between the wildlings of the continuous population and the offspring samples from the isolated population only by the number of sampled candidate parents, which was set as 80 and $95 \%$ respectively. The confidence level for the assignment of the 
Table 1 Mean values of genetic diversity parameters and inbreeding coefficients in Vateria indica across life stages from a continuous and an isolated population

\begin{tabular}{lllllll}
\hline & $\mathrm{N} 934$ & $\mathrm{~N}_{\mathrm{A}}$ & Ho & He & Allelic richness* & Fis \\
\hline SIP adults & 85 & $5.25 \pm 0.52$ & $0.560 \pm 0.068$ & $0.576 \pm 0.057$ & $5.21 \pm 0.52$ & $0.024(-0.05 ; 0.116)$ \\
LCP adults & 155 & $8.50 \pm 0.60$ & $0.656 \pm 0.037$ & $0.690 \pm 0.033$ & $7.90 \pm 0.60$ & $0.041(0.015 ; 0.068)$ \\
SIP wildlings & 117 & $5.92 \pm 0.47$ & $0.583 \pm 0.051$ & $0.603 \pm 0.051$ & $5.72 \pm 0.45$ & $0.024(-0.009 ; 0.056)$ \\
LCP wildlings & 119 & $7.83 \pm 0.82$ & $0.643 \pm 0.047$ & $0.708 \pm 0.027$ & $7.42 \pm 0.74$ & $0.072(-0.007 ; 0.153)$ \\
SIP seed & 259 & $5.08 \pm 0.45$ & $0.492 \pm 0.043$ & $0.608 \pm 0.045$ & $4.77 \pm 0.40$ & $0.155(0.096 ; 0.211)$ \\
SIP nursery seedlings & 199 & $5.58 \pm 0.50$ & $0.513 \pm 0.042$ & $0.611 \pm 0.042$ & $5.07 \pm 0.42$ & $0.110(0.056 ; 0.161)$ \\
\hline
\end{tabular}

Figures in brackets are $95 \%$ confidence intervals obtained from jack-knifing over loci, same letters in superscript indicate of non-overlapping confidence intervals

$N_{A}$ mean number of alleles, \pm Standard error

* Based on 77 diploid individuals, SIP small isolated population, LCP large continuous population

two most likely parents was set at $85 \%$. Special attention was given to assignments where both putative parents were beyond $100 \mathrm{~m}$ from the wildling location. Because candidate parents at larger distances have higher chance of being false positives (Chybicki and Burczyk 2010) and because the probability of erroneous assignments increases with long-distance seed dispersal, we considered those events only if they were assigned to two parents at the minimum $90 \%$ significance threshold.

Pollen dispersal was calculated for each offspring sample as the distance between the two most likely parents. Because the seeds are primarily dispersed by gravity we assume that pollen dispersal always exceeds seed dispersal (except in the case of selfing). Thus the seed dispersal distance was calculated as the distance between the wildling and the nearer parental tree following Finger et al. (2011).

To investigate if historic levels of gene flow differ between the two populations and to investigate temporal changes in gene flow, we additionally estimated levels of historic gene dispersal distances $(\sigma)$ of the two adult populations based on FSGS. These estimates were computed with SPAGeDi 1.3a (Hardy and Vekemans 2002) based on 10,000 permutations of locations and genes. Estimates of $\sigma$ are sensitive to the effective density of the population. Effective density can be estimated by multiplying the census density by the ratio of effective population size to the census population size (Hardy and Vekemans 2002). Demographic studies demonstrated that effective population sizes in plant populations range approximately from half to a tenth of the census population (Frankham 1995). Based on natural densities $\left(D_{N}\right)$ of adult $V$. indica trees we thus estimated a range of $\sigma$ based on $\mathrm{D}_{\mathrm{N}} /$ 2 and $\mathrm{D}_{\mathrm{N}} / 10$ as estimates of effective population densities. Because the census densities of the studied populations are unlikely to represent their historic densities we estimated $\mathrm{D}_{\mathrm{N}}$ as $104 \mathrm{~V}$. indica trees $(\mathrm{DBH}>10 \mathrm{~cm})$ per ha based on a former study in a 28 ha permanent plot located in pristine unlogged forest within Kodagu district (Pascal and Pelissier 1996).

\section{Patterns of FSGS}

To evaluate the levels of FSGS we investigated the correlation of pairwise relatedness ( $r$ ) and the kinship coefficient (F) (Loiselle et al. 1995) over the pairwise spatial distance of the samples with GenAlEx (Peakall and Smouse 2006) and SPAGeDi 1.3a (Hardy and Vekemans 2002). The levels of FSGS were computed separately for the adults of both populations and the wildlings of the isolated population. We defined six distance classes for the pairwise comparisons of kinship up to 640 metres (end point of each distance class was $10,20,40,80,160$ and $640 \mathrm{~m}$ ). The distance classes were chosen to ensure in all three cohorts sufficient pairwise distances (with a minimal number of 58 pairs in the shortest distance class of the adults from the isolated population). The wildlings from the continuous population had to be excluded because of insufficient numbers of pairwise distances between 20 and $160 \mathrm{~m}$. For comparing the intensity of FSGS between the two adult cohorts and the wildlings we calculated the Spstatistic (Vekemans and Hardy 2004), defined as $\mathrm{Sp}=-\hat{\mathrm{b}}_{\mathrm{F}} /\left(1-\hat{\mathrm{F}}_{(1)}\right)$, where $\hat{\mathrm{b}}_{\mathrm{F}}$ is the mean regression slope of the kinship coefficient over the natural logarithm (ln) of the distance and $\hat{\mathrm{F}}_{(1)}$ is the mean kinship of the sample pairs within the first distance class $(0-10 \mathrm{~m})$. To test if relatedness at the different distance classes differs significantly, we computed the squared paired-sample $t$ test statistic $\left(t^{2}\right)$ described as single class heterogeneity test in (Smouse et al. 2008) and implemented in the program GenAlEx $6.5 \mathrm{~b} 3$ (Peakall and Smouse 2006). Significance of $p$ values of the heterogeneity test was only considered when $p<0.01$ as recommended in Banks and Peakall (2012). We compared the intensity ( $\hat{\mathrm{b}}_{\mathrm{F}}$ and $\mathrm{SP}$ ) of the observed 
FSGS with four other dipterocarp species. For these comparisons we reanalysed the data published in (Kettle et al. 2011a) and Finger (Finger et al. 2012) using 20, 40, 80, 160 , and $1,280 \mathrm{~m}$ as the end points of distance classes, combined with the data from this study.

\section{Effects of inbreeding on seedling performance}

Based on the parentage analysis of the nursery raised seedlings (described above), we calculated the individual kinship coefficient (Loiselle et al. 1995) of the two most likely parents as a measure of inbreeding in SPAGeDi 1.3a (Hardy and Vekemans 2002). To investigate the effect of inbreeding on growth performance we split up the nursery raised seedlings into outbred and selfed progeny. The outbred seedlings were further split into two groups at the median of their kinship coefficients to investigate the effect of mating between more related individuals. Differences in size variation after 21 months of growth among the three groups of seedlings were tested with an ANOVA. To investigate for significant differences among the mean sizes of the three groups of samples we applied a post hoc Tukey HSD test implemented in R 1.13.1 (R Development Core Team 2011).

\section{Results}

Genetic diversity, inbreeding and differentiation

At the 12 loci analysed across all samples between five and 15 alleles were detected with 117 alleles in total. When estimating the deviations from HWE and null allele frequencies across the 12 microsatellite loci based on the adult samples from the continuous site only, we detected no evidence for any deviations from HWE and low frequencies of null alleles (with 0.08 in locus Vi45 having the highest estimate). The same analysis applied to the small isolated population revealed homozygous excess at four loci (Vat 14, Vi18, Vat 14 and Vi18). Because we can rule out differences in the processing of the samples we interpret these findings as genuine deviations from HWE.

Genetic diversity measured as number of effective alleles, expected heterozygosity and allelic richness within the large continuous site and within the small isolated site remained at similar levels when comparing adults and wildlings. In this population the seed samples and the nursery raised seedlings showed a slightly reduced allelic richness compared to adults. When comparing genetic diversity between the two sites, the isolated site had significantly lower genetic diversity across all life stages (Table 1).
The inbreeding coefficients $\left(\mathrm{F}_{\mathrm{is}}\right)$ of adults and wildlings from the isolated site and the wildlings from the continuous site did not differ significantly from zero. The $F_{\text {is }}$ value of the adult cohort from the river population differed marginally from zero. When comparing the inbreeding coefficients $\left(\mathrm{F}_{\mathrm{is}}\right)$ of adults and wildlings within sites they did not differ. The $F_{\text {is }}$ values of the nursery raised seedlings and the seed samples from the isolated population were significantly higher than zero and significantly higher than the $F_{\text {is }}$ values of the wildlings within the same site (Table 1).

The pairwise comparisons of $\mathrm{F}_{\mathrm{st}}$ among the sites and cohorts showed that only the adults and their wildlings from the isolated site as well as the seed and nursery samples did not differ significantly from each other. All the other pairwise $\mathrm{F}_{\mathrm{st}}$ values differed significantly at the $5 \%$ level, which was $0.3 \%$ after applying a standard Bonferroni correction (Table 2).

Patterns of gene flow

\section{Contemporary pollen dispersal in the isolated population}

In the isolated site we applied parentage analysis to estimate pollen dispersal distances in the wildlings, seed and nursery-raised seedlings (Fig. 2). We were able to assign $85 \%(N=99)$ of the wildling samples to the two most likely parent pairs at the $85 \%$ confidence level, with $83 \%(N=82)$ of the pollination events being within $100 \mathrm{~m}$. Only four per cent $(N=4)$ of wildlings were from selfing events. We detected three long-distance pollen dispersal events between 3 and $3.4 \mathrm{~km}$ from the neighbouring continuous site. The average pollen dispersal distance in the wildlings was $167 \mathrm{~m}$ (median $=39 \mathrm{~m})$. In the seed samples the assignment rate was $69 \%(N=180)$ of which $86 \%(N=154)$ were pollen dispersal events within $100 \mathrm{~m}$. The selfing rate was $28 \%$ $(N=51)$. Five seed samples were assigned to putative fathers from the continuous site at distances between 2.3 and $3.3 \mathrm{~km}$ from the maternal tree. Over all assigned seed samples the average pollen dispersal distance was $139 \mathrm{~m}$ $($ median $=22 \mathrm{~m})$.

The parentage analysis of the nursery seedlings assigned $67 \%(N=133)$ of the samples to the two most likely parents. Eighty-seven per cent $(N=116)$ of the assigned nursery samples were derived from pollination events within $100 \mathrm{~m}$ and $29 \%(N=38)$ were selfing events. Four nursery seedlings were assigned to fathers from the neighbouring continuous site with distances between 2.4 and $3.2 \mathrm{~km}$. In the nursery seedlings the average pollen dispersal distance was $138 \mathrm{~m}$ (median $=21 \mathrm{~m}$ ).

Based on the assumption that all unassigned seeds were from outcrossing, we estimated a minimum selfing rate as 
Table 2 Pairwise Fst values across populations and cohorts of Vateria indica

\begin{tabular}{|c|c|c|c|c|c|c|}
\hline & SIP adults & LCP adults & SIP wildlings & LCP wildlings & SIP seed & SIP nursery \\
\hline SIP adults & 0 & & & & & \\
\hline LCP adults & $0.071 *$ & 0 & & & & \\
\hline SIP wildlings & 0.0012 & $0.062 *$ & 0 & & & \\
\hline LCP wildlings & $0.1081 *$ & $0.024 *$ & $0.0979 *$ & 0 & & \\
\hline SIP seed & $0.0097 *$ & $0.0639 *$ & $0.0129 *$ & $0.1013 *$ & 0 & \\
\hline SIP nursery & $0.0142 *$ & $0.0691 *$ & $0.0162 *$ & $0.1026^{*}$ & 0.0019 & 0 \\
\hline
\end{tabular}

$* p$ values below 0.003 which is the adjusted nominal level for multiple comparisons at the $5 \%$ level

SIP small isolated population, LCP large continuous population

Fig. 2 Frequency distribution of pollen dispersal distances in the isolated Vateria indica population obtained from parentage analysis from different offspring life stages

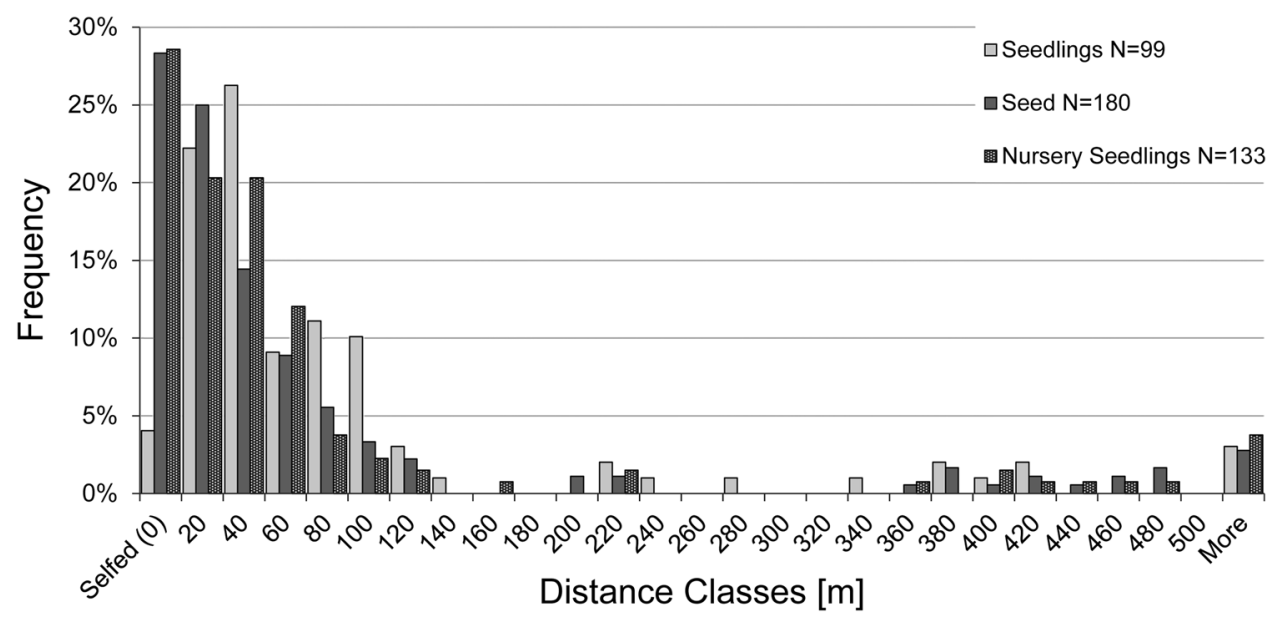

$3 \%$ in the wildlings, $20 \%$ in the seed and $19 \%$ in the nursery samples.

\section{Contemporary pollen dispersal in the continuous site}

We could assign $41 \%(N=49)$ of the wildlings at the $85 \%$ confidence level. Twenty-two of the assigned wildlings were due to selfing of which 21 were collected under two mother trees isolated from the next conspecifics by 60 and $70 \mathrm{~m}$. This equates to a $45 \%$ selfing rate of the assigned samples. Assuming that we had assigned all of the selfed progeny within our sample we estimated the minimum selfing rate within our samples to be at least $18 \%$ (22 out of 119 samples). The average pollen dispersal distance was $158 \mathrm{~m} \quad($ median $=17 \mathrm{~m})$ with a maximum of $2,167 \mathrm{~m}$ with no pollen inflow from the isolated site.

\section{Patterns of seed dispersal in the isolated and the continuous sites}

Seed dispersal was almost the same in all four sampling schemes with seed dispersal distances ranging from 14 to
Table 3 Gene dispersal sigma $(\sigma)$ in $\mathrm{m}$ of Vateria indica computed in SPAGeDi 1.3a (Hardy and Vekemans 2002) $D_{N}$ : assumed historic density of $104 \mathrm{~V}$. indica trees based on Pascal and Pelissier(1996), SE standard error by jack-knifing over loci

\begin{tabular}{lll}
\hline $\begin{array}{l}\text { Assumed historic } \\
\text { effective density }\end{array}$ & Adults SIP & Adults LCP \\
\hline $\mathrm{D}_{\mathrm{N}} / 2(52$ trees/ha) & $25.2(\mathrm{SE}=4.2)$ & $22.5(\mathrm{SE}=1.9)$ \\
$\mathrm{D}_{\mathrm{N}} / 10(10.4$ trees/ha) & $58.8(\mathrm{SE}=9.0)$ & $58.7(\mathrm{SE}=7.6)$ \\
\hline
\end{tabular}

$S I P$ small isolated population, $L C P$ large continuous population

$19 \mathrm{~m}$ (median 5-8 m). Between $87 \%$ (156 seed samples) and $96 \%$ (128 nursery samples) of the seeds were dispersed within $40 \mathrm{~m}$.

\section{Indirect estimates of historic gene flow}

The indirect estimate of gene dispersal distances $(\sigma)$ computed with SPAGeDi 1.3a (Vekemans and Hardy 2004) ranged from $23 \mathrm{~m}$ and increased with decreasing effective density up to $59 \mathrm{~m}$. When comparing double standard error ranges, the gene dispersal estimates did not differ significantly between the isolated and continuous adult populations (Table 3 ). 
Table 4 Slope of the kinship coefficient over the ln distance $\left(b_{\mathrm{Ld}}\right)$ and Sp-statistic to compare the intensity of the FSGS between the adults and wildlings from a small isolated population (SIP) as well as adults from a large continuous population LCP in Vateria indica calculated over 10, 20, 40, 80, 160 and $640 \mathrm{~m}$ as end points of the distance class intervals

\begin{tabular}{lll}
\hline & $\mathrm{b}_{\mathrm{Ld}}$ (Standard error) & $\begin{array}{l}\text { Sp (Standard } \\
\text { error) }\end{array}$ \\
\hline Vateria indica adults SIP & $\mathrm{b}_{\mathrm{Ld}}=-0.027(0.005)$ & $0.027(0.005)$ \\
Vateria indica wildlings SIP & $\mathrm{b}_{\mathrm{Ld}}=-0.025(0.004)$ & $0.028(0.004)$ \\
Vateria indica adults LCP & $\mathrm{b}_{\mathrm{Ld}}=-0.023(0.003)$ & $0.026(0.003)$ \\
\hline
\end{tabular}

Patterns of fine scale spatial genetic structure

The intensity of the FSGS quantified by the Sp-statistic showed no significant difference when comparing the adults from the continuous site with the adults or the wildlings from the isolated site (Table 4). Despite the similar intensity of FSGS the kinship of the adults and wildlings from the isolated site were significantly different from zero only up to $40 \mathrm{~m}$ whereas the kinship coefficient of the adults from the continuous site was significantly different from zero up to $160 \mathrm{~m}$ (Fig. 3). Indeed, the single class heterogeneity test indicated that the adults from the continuous site had a significantly higher relatedness at the 40, 80 and $160 \mathrm{~m}$ distance class $(p<0.01)$.

The re-calculation of the FSGS based on different distance intervals revealed that the adult $V$. indica populations had a consistently more intense FSGS than the three dipterocarps from single large continuous forests investigated by Kettle et al. (2011a) in Borneo. Contrastingly, the extremely rare and fragmented species endemic to Seychelles, Vateriopsis sechellarum had a much more intense FSGS than observed in $V$. indica (Table 5).
Performance of nursery raised seedlings

Of the 202 nursery raised seedlings, 199 were successfully genotyped. Based on the parentage analysis we first split the 133 assigned nursery seedlings into selfed $(N=38)$ and outbred individuals $(N=95)$ to investigate if performance differed. The kinship coefficients of the parent pairs (Loiselle et al. 1995) of the non-selfed progeny were normally distributed around the mean $(0.120)$ with all except four observations lying within the $95 \%$ confidence interval. To investigate the effect of bi-parental inbreeding and to achieve more even sample sizes we split the non-selfed progeny according to the median kinship coefficient of the parent pairs $(0.95)$ which was slightly lower than the mean. This resulted in the outbred nursery seedlings in a group of 48 individuals with a low kinship of parent pairs $(<0.1)$ and 47 individuals with a high kinship of parent pairs $(>0.1$, of which one individual without size measurement had to be excluded from the analysis). As indicated by the ANOVA there was significant variation $\left(\mathrm{F}_{2,129}=6.85, p=0.0015\right)$ in size among the three groups. The mean height after 21 months of growth in the selfed individuals was $31 \mathrm{~cm}$, which in a Tukey HSD test differed significantly from the average size $(44 \mathrm{~cm})$ of outbred individuals with a low kinship of parent pairs $(p=0.001)$ and from the average size $(40 \mathrm{~cm})$ of outbred individuals with a high kinship of parent pairs ( $p=0.03)$. The two groups of outbred nursery seedlings did not differ significantly ( $p=0.56$; Fig. 4$)$.

\section{Discussion}

To sustain high levels of biodiversity in complex agro-forest landscapes, constituent tree species and their underlying FGR must be maintained. Our study indicates that in a highly
Fig. 3 Fine-scale spatial genetic structure of Vateria indica for the adult cohort of a continuous population, the adult cohort and the wildling cohort of an isolated population. The distance classes are: $10,20,40$, 80,160 and $640 \mathrm{~m}$

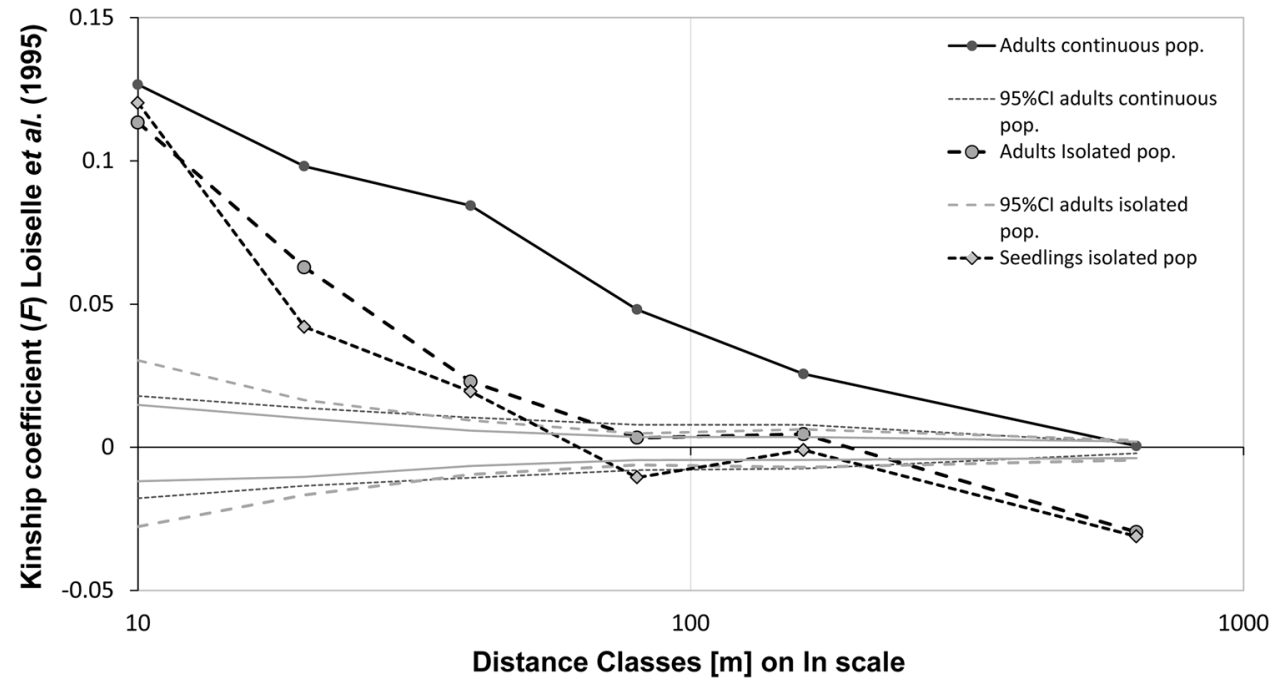


Table 5 Comparison of the slope of kinship over the natural logarithm of the distance $\left(b_{\mathrm{Ld}}\right)$, the intensity of the FSGS $(\mathrm{Sp})$, mean pollen dispersal distance $\left(\mathrm{d}_{\mathrm{p}}\right)$ of assigned embryos or on seedlings for Vateriopsis sechellarum and mean number of alleles $\left(\mathrm{N}_{\mathrm{A}}\right)$ across adult

\begin{tabular}{llllr}
\hline & $\mathrm{b}_{\mathrm{Ld}}$ & $\mathrm{Sp}$ & $\mathrm{d}_{\mathrm{p}}(\mathrm{m})$ & Number of loci \\
\hline Vateria indica SIP & $-0.024(0.0047)$ & $0.026(0.005)$ & $139(37.2)$ & 12 \\
Vateria indica LCP & $-0.023(0.0030)$ & $0.026(0.003)$ & $\mathrm{NA}$ & 12 \\
Shorea xantophylla & $-0.007(0.0022)$ & $0.007(0.002)$ & $119(8.4)$ & 6 \\
Parashorea tomentella & $-0.011(0.0027)$ & $0.012(0.003)$ & $\mathrm{NA}$ & 6 \\
Dipterocarpus grandiflorus & $-0.002(0.0006)$ & $0.002(0.0007)$ & $14.7)$ & 6 \\
Vateriopsis sechellarum & $-0.032(0.0041)$ & $0.040(0.005)$ & $107(52.8)$ & 10 \\
\hline
\end{tabular}

Figures in parentheses represent standard errors

fragmented human modified landscape FGR of an important endemic timber species are well conserved. Our investigation of contemporary gene flow suggests that although the two small isolated patches are genetically insular, they are connected to each other and sufficiently large to prevent genetic erosion. Interestingly, the parentage analysis indicates relatively frequent selfing in $V$. indica. Selfed progeny exhibit poorer performances under nursery conditions, and selection favours outbred progeny under natural conditions. Below we discuss the processes which might help retain genetic diversity within populations of dipterocarp tree species in human dominated landscapes and provide some recommendations for the conservation of FGR in the context of restoration. The comparison of FSGS and pollen flow with four other dipterocarp species provide insights into the potential genetic susceptibility of dipterocarp species to fragmentation more generally.

Do small isolated forest patches retain comparable levels of genetic diversity to a larger more continuous forest?

Our study demonstrates no loss of genetic diversity from the adult to the wildling stage in the small isolated or the trees from a small isolated population (SIP) and from a large continuous population (LCP) of Vateria indica with four other dipterocarp species (data on Vateriopsis sechellarum is from (Finger et al. 2012) and the other three dipterocarp species from (Kettle et al. 2011a)) larger more continuous forest. This suggests that a sufficient number of adult trees are contributing genes to the current juvenile cohort. Indeed, $86 \%$ of the trees in the isolated patches were parents of the progeny samples. This is in contrast to other empirical studies comparing adults and wildlings of fragmented tree populations that show lower genetic diversity in the juveniles (e.g. Kettle et al. 2007; Sebbenn et al. 2011; Finger et al. 2012). Within the isolated patches we detected significantly lower genetic diversity than in the larger patch. This could be due to an initial sampling effect associated with fragmentation which retained fewer alleles than in the pre-fragmented forest (discussed below).

Do patterns of gene flow and genetic structure differ across life stages and between continuous and isolated patches?

\section{Contemporary pollen dispersal in small isolated patches}

Comparing the pollen dispersal pattern of the wildlings with the seed samples and the nursery reared progeny demonstrated that pollen was dispersed predominantly within $100 \mathrm{~m}$ (Fig. 2). Interestingly, only a tiny proportion
Fig. 4 Mean size of nursery raised Vateria indica after 21 months of growth grouped by different levels of inbreeding estimated from the kinship of parent pairs. Error bars are $2 \times$ standard error. Differing letters $(a, b)$ indicate significant differences between groups at the $95 \%$ confidence levels $(p<0.05)$ based on a Tukey HSD test

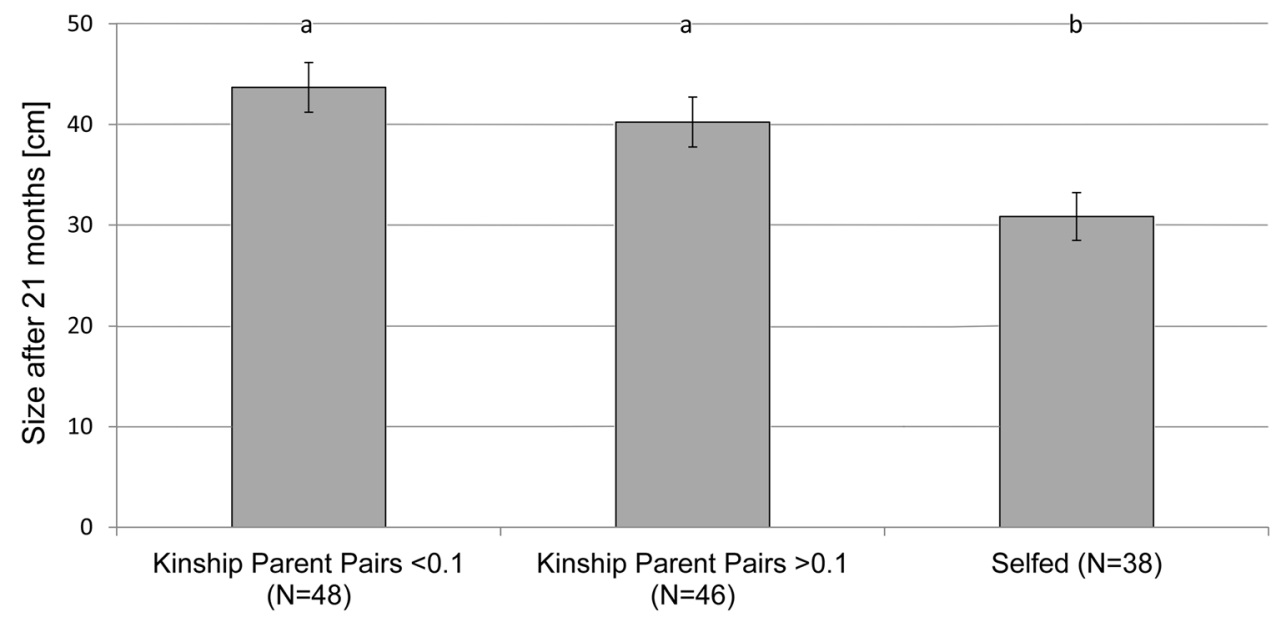


of the wildlings, seed and the nursery reared progeny (2-3\%) were sired by trees from the large continuous population as pollen in-flow. However, even these rare long distance pollen dispersal events could be sufficient to maintain the genetic diversity in isolated populations (Ellstrand 1992; White et al. 2002). Also, we cannot exclude the possibility that some of the unassigned samples might have been the result of long-distance pollen dispersal events.

The main difference between the pollen dispersal estimates for the three offspring groups was the considerably lower minimum selfing rate in the wildlings $(3 \%)$ compared to the minimum selfing rate estimated for the seed samples $(20 \%)$ and the nursery samples $(19 \%)$. This elevated selfing caused an excess of homozygotes, which was reflected in the higher inbreeding coefficients $\left(\mathrm{F}_{\mathrm{is}}\right)$ and the significant different $\mathrm{F}_{\mathrm{st}}$-values in the seed and nursery seedlings compared to the adults and the wildlings of the isolated population (Tables 1, 2). Because the seed, wildlings and nursery reared seedlings collected from the isolated population were all progeny from the same flowering season, we assume that the actual selfing rate was the same for all. Therefore the lower selfing rate detected in the wildlings was due to higher mortality in selfed seed compared to outbred seed, which indicates postzygotic selection against selfing. Interestingly, Ghazoul and Satake (2009) proposed that selfed seeds of dipterocarps may dilute the impact of seed predators by acting as a seed predator sink, thereby increasing the survival of outcrossed seeds. In our case a similar but delayed process might act at the seedling stage.

\section{Contemporary pollen dispersal in the large continuous forest}

We detected occasional realised long-distance pollen dispersal events in the wildlings from the continuous forest, confirming that gene flow can effectively occur at landscape scales in this species. Of the three events beyond $500 \mathrm{~m}$ two were beyond $2 \mathrm{~km}$, but we did not detect a single father from the isolated population. Rare long distance pollen dispersal beyond $500 \mathrm{~m}$ is consistent with previously published pollen dispersal estimates made for Dipterocarpus tempehes in a continuous forest. D. tempehes is commonly pollinated by the giant honey bee $A$. dorsata (Kenta et al. 2004). Indeed, $5 \%$ of the foraging distances of $A$. dorsata have been recorded beyond $2.5 \mathrm{~km}$ with maximum flying distances between 13.2 and $21.8 \mathrm{~km}$ (Dyer and Seeley 1991).

It is noteworthy that we detected a relatively high selfing rate with 22 of the 49 assigned wildlings being selfed. Twenty-one of these 22 selfing events were from wildlings collected below two isolated trees (isolated by 60 and $70 \mathrm{~m}$ from conspecifics). Increased selfing in a predominantly outcrossing plant species might be a strategy to assure reproduction when mating partners are lacking (Eckert et al. 2010), which might reflect asynchrony among flowering conspecifics. We refrained from comparing selfing rates in wildings among the continuous and isolated patch because these were sampled in different years and therefore might have experienced different mortality rates.

\section{Patterns of seed dispersal in the isolated} and the continuous population

Estimates of seed dispersal were comparable across all the progeny samples from the isolated and continuous forest, with average seed dispersal not exceeding $19 \mathrm{~m}$. This is consistent with the idea that seed dispersal is predominantly by gravity. It was surprising that between 4 and $13 \%$ of the seed were dispersed beyond $40 \mathrm{~m}$ indicating occasional longer distance seed dispersal. It is possible that there is secondary dispersal by rodents. We have occasionally observed teeth marks on seed coats (Ismail pers. obs. 2009, 2011), hinting at rodent seed predation. Secondary seed dispersal by forest rats has been reported in another dipterocarp species (Wells and Bagchi 2005), but is generally thought to be rare.

\section{Indirect estimates of historic gene flow}

Because the Sp-statistic and the slope of the decline of kinship with the $\ln$ distance of the two adult populations were almost the same, we expected similar historic gene flow patterns. Indeed the indirect estimates of historic gene flow indicated that the two adult populations do not differ (Table 3) and that the isolated patches are more likely a remnant of more continuous forest and not a result of a recent founder event. If a founder event had occurred, a more intense kinship structure and greater differentiation would be a likely signal as shown in the extreme case of $V$. seychellarum (see Finger et al. 2012) but not in V. Indica.

Recommendations for the conservation and management of genetic resources in $V$. indica across agro-forest landscapes

By comparing a continuous population with an isolated population of $V$. indica our study offers insights into how forest genetic resources of V.indica can be managed for restoration of degraded wet evergreen forest of the Western Ghats. Vateria indica has a great potential for restoration as it grows relatively rapidly and survives well in degraded forest (Rai 1990).

Our results demonstrate that selfed individuals are more likely to survive under benign nursery conditions than 
under the harsher natural conditions of the forest floor. Effective selection against selfed and inbred wildlings under natural forest conditions has been observed in other dipterocarp species (Lee et al. 2000; Naito et al. 2005). Early acting selection appears to be common in tree species (Petit and Hampe 2006) and might in many species be less effective when seedlings are grown in nurseries. Elevated inbreeding under nursery conditions has been reported in restoration of other rare tree species (Kettle et al. 2008). Where viable, restoration efforts using direct seeding of $V$. indica over planting nursery reared seedlings, should help to ensure natural selection against maladapted individuals and avoid establishment of inbred populations. However, as many forest species cannot establish from seed under open conditions, nursery reared seedlings may still be an essential part of restoration programmes in highly degraded forest (Gunaratne et al. 2010). In these cases selecting only the most vigorous progeny should help to reduce the proportion of inbred seedlings for restoration.

Our results suggest that to capture genetic diversity in seed or wildling collections for restoration, collections should cover several $\mathrm{km}$. To minimise relatedness, sampling intervals should exceed $40 \mathrm{~m}$. Ideally seed collection should ensure pairwise distances beyond $160 \mathrm{~m}$, since we know from the FSGS that beyond this distance pairs of individuals are not more related than random. Similar strategies could be applied to most other dipterocarp species as they usually have limited seed dispersal and therefore often exhibit significant FSGS (Harata et al. 2012; Kettle et al. 2011a; Finger et al. 2012).

How does $V$. indica compare to other dipterocarp species?

The comparison of FSGS in V.indica with the three dipterocarp species from a continuous forest in Borneo, indicates that FSGS in $V$. indica is more intense. This difference is probably driven by the clumped distribution, the restricted habitat range and the very restricted seed dispersal of $V$. indica. As the three Bornean species cover a range of pollinator syndromes and pollen dispersal distances (Kettle et al. 2011b), varying pollen dispersal distances seem less important in generating the more intense FSGS in $V$. indica. In context of dipterocarp pollination ecology, it is worth mentioning that $S$. xanthophylla is predominantly pollinated by tiny pollinators such as thrips (Kettle et al. 2011b) which are thought to be important pollinators for many of the species rich Shorea genus (Appanah 1990). Interestingly, S. xanthophylla and and $P$. tomentella showed no evidence of selfing (Kettle et al. 2011b). The comparison with $V$. seychellarum shows that the level of relatedness decreases faster with distance than in $V$. indica. As the seed and pollen dispersal distances are almost the same, this difference is presumably driven by a strong genetic bottleneck, much smaller population sizes and a much higher selfing rate $(53 \%)$ in V. seychellarum.

Generally, self-compatible tree species show more intense FSGS than outcrossing self-incompatible species (Vekemans and Hardy 2004). Additionally, it was shown that fragmentation affects genetic diversity in outcrossing plant species more than in self-compatible species (Honnay and Jacquemyn 2007; $\mathrm{Ng}$ et al. 2009). We interpret the low levels of inbreeding in the wildlings of the isolated population as a result of efficient selection against maladapted individuals combined with sufficiently diverse pollen. Therefore $V$. indica as a self-compatible species with occasional long-distance pollen flow seems well buffered against the negative effects of increased biparental inbreeding caused by fragmentation.

It has been shown that spatial isolation can change matting patterns leading to increased selfing in many predominantly outcrossing plant species, and this acts as an important means of reproductive assurance in the absence of pollinators or mating partners (Eckert et al. 2010). Increased selfing rates in response to fragmentation in dipterocarp species have been shown to increase inbreeding in mature seed (Obayashi et al. 2002; Naito et al. 2008) as well as in wildlings (Fukue et al. 2007; Finger et al. 2012). With the growing knowledge of FSGS, pollen and seed dispersal distances in dipterocarps, it can be inferred that self-incompatible dipterocarps with strong FSGS and limited pollen dispersal are likely to be especially vulnerable to fragmentation. Species with limited seed dispersal, naturally occurring at high local densities should be buffered against deleterious effects of inbreeding by selfcompatibility combined with effective selection against maladapted selfed individuals. The robustness of an isolated forest patch is largely determined by distance to the next population, pollen dispersal distance and local population size. Ideally studies should include multiple replicates of sites with varying population sizes and degree of isolation. However, this is not always a feasible option. Our study is an example of an important tropical tree species distributed across a complex landscape and provides insights into the essential processes that conserve forest genetic resources in this context. These results are especially useful given the paucity of knowledge on the genetic consequences of fragmentation for dipterocarp species across their range, despite their continued and rapid fragmentation.

Acknowledgments We thank the reliable field assistants Navin $\mathrm{H}$. Kumar, Monappa C.S., Chengappa S.K. and particularly Range Gowda, Harsha C. and the late Umesh who took care for the nursery. The tedious single DNA extractions conducted by Sandeep Sen and Shruthi Jayappa are esteemed a lot. We are indebted to Aline Finger 
who provided without hesitation her data on Vateriopsis seychellarum. The comments and corrections of Prof. Mike Bruford and anonymous referees helped to improve the manuscript and are greatly appreciated. Fragment analysis was conducted at the Genetic Diversity Centre (GDC) of ETH Zürich. This research was funded by ETH Zürich under the Grant number ETH-22 08-2.

\section{References}

Aguilar R, Ashworth L, Galetto L, Aizen MA (2008) Plant reproductive susceptibility to habitat fragmentation: review and synthesis through a meta-analysis. Ecol Lett 9(8):968-980

Aizen MA, Feinsinger P (1994) Forest fragmentation, pollination, and plant reproduction in a chaco dry forest, Argentina. Ecology 75(2):330-351

Anand M, Krishnaswamy J, Kumar A, Bali A (2010) Sustaining biodiversity conservation in human-modified landscapes in the Western Ghats: remnant forests matter. Biol Conserv 143(10): 2363-2374

Appanah S (1990) Plant-pollinator interactions in Malaysian rain forests. In: Bawa KS, Hadley M (eds) Reproductive ecology of tropical forest plants, vol 7., Man and biosphere seriesUNESCOParthenon, Paris, pp 85-101

Ashton PS (1988) Dipterocarp biology as a window to the understanding of tropical forest structure. Annu Rev Ecol Syst 19:347-370

Ashton PS (1998) Vateria indica. In: IUCN 2013. IUCN red list of threatened species. Version 2013.2. www.iucnredlist.org. Accessed 28 Nov 2013

Banks SC, Peakall ROD (2012) Genetic spatial autocorrelation can readily detect sex-biased dispersal. Mol Ecol 21(9):2092-2105

Breed MF, Marklund MH, Ottewell KM, Gardner MG, Harris JB, Lowe AJ (2012) Pollen diversity matters: revealing the neglected effect of pollen diversity on fitness in fragmented landscapes. Mol Ecol 21(24):5955-5968

Chybicki IJ, Burczyk J (2010) NM+: software implementing parentage-based models for estimating gene dispersal and mating patterns in plants. Mol Ecol Res 10(6):1071-1075

Dick CW (2001) Genetic rescue of remnant tropical trees by an alien pollinator. Proc R Soc Lond 268(1483):2391-2396

Durand M (1997) Pondy papers in ecology, vol 3., Architecture and growth strategy of two evergreen species of the Western Ghats (South India). Knema attenuata (Myristicaceae) and Vateria indica (Dipterocarpaceae)French Institute Pondicherry, Pondicherry, p 39

Dyer FC, Seeley TD (1991) Dance dialects and foraging range in three Asian honey bee species. Behav Ecol Sociobiol 28(4): 227-233

Eckert CG, Kalisz S, Geber MA, Sargent R, Elle E, Cheptou P-O, Goodwillie C, Johnston MO, Kelly JK, Moeller DA, Porcher E, Ree RH, Vallejo-Marín M, Winn AA (2010) Plant mating systems in a changing world. Trends Ecol Evol 25(1):35-43

Ellstrand NC (1992) Gene flow by pollen: implications for plant conservation genetics. Oikos 63:77-86

Finger A, Kettle CJ, Kaiser-Bunbury CN, Valentin T, Doudee D, Matatiken D, Ghazoul J (2011) Back from the brink: potential for genetic rescue in a critically endangered tree. Mol Ecol 20(18):3773-3784

Finger A, Kettle CJ, Kaiser-Bunbury CN, Valentin T, Mougal J, Ghazoul J (2012) Forest fragmentation genetics in a formerly widespread island endemic tree: Vateriopsis seychellarum (Dipterocarpaceae). Mol Ecol 21(10):2369-2382

Frankham R (1995) Effective population size/adult population size ratios in wildlife: a review. Genet Res 66(02):95-107
Frankham R (2005) Genetics and extinction. Biol Conserv 126(2):131-140

Fukue Y, Kado T, Lee SL, Ng KKS, Muhammad N, Tsumura Y (2007) Effects of flowering tree density on the mating system and gene flow in Shorea leprosula (Dipterocarpaceae) in Peninsular Malaysia. J Plant Res 120(3):413-420

Garcia C, Arroy JM, Godoy JA, Jordano P (2005) Mating patterns, pollen dispersal, and the ecological maternal neighbourhood in a Prunus mahaleb L. population. Mol Ecol 14(6):1821-1830

Garcia CA, Bhagwat SA, Ghazoul J, Nath CD, Nanaya KM, Kushalappa CG, Raghuramulu Y, Nasi R, Vaast P (2010) Biodiversity conservation in agricultural landscapes: challenges and opportunities of coffee agroforests in the Western Ghats. India Conserv Biol 24(2):479-488

Ghazoul J (2005) Pollen and seed dispersal among dispersed plants. Biol Rev 80(03):413

Ghazoul J, Satake A (2009) Nonviable seed set enhances plant fitness: the sacrificial sibling hypothesis. Ecology 90(2):369-377

Goudet J (1995) FSTAT (Version 1.2): a computer program to calculate F-statistics. J Hered 86(6):485-486

Gunaratne AMTA, Gunatilleke CVS, Gunatilleke IAUN, Madawala Weerasinghe HMSP, Burslem DFRP (2010) Barriers to tree seedling emergence on human-induced grasslands in Sri Lanka. J Appl Ecol 47(1):157-165

Harata T, Nanami S, Yamakura T, Matsuyama S, Chong L, Diway BM, Tan S, Itoh A (2012) Fine-scale spatial genetic structure of ten Dipterocarp tree species in a Bornean rain forest. Biotropica 44(5):586-594

Hardy OJ, Vekemans X (2002) SPAGeDi: a versatile computer program to analyse spatial genetic structure at the individual or population levels. Mol Ecol Notes 2(4):618-620

Honnay O, Jacquemyn H (2007) Susceptibility of common and rare plant species to the genetic consequences of habitat fragmentation. Conserv Biol 21(3):823-831

Ismail SA, Ghazoul J, Ravikanth G, Uma Shaanker R, Kushalappa CG, Kettle CJ (2012) Does long-distance pollen dispersal preclude inbreeding in tropical trees? Fragmentation genetics of Dysoxylum malabaricum in an agro-forest landscape. Mol Ecol 21(22):5484-5496

Ismail SA, Buser A, Uma Shaanker R, Ravikanth G, Ghazoul J, Kettle CJ (2013) Development of polymorphic microsatellite markers for the critically endangered and endemic Indian dipterocarp, Vateria indica L. (Dipterocarpaceae). Conserv Genet Resour $5(2): 465-467$

ITTO (2008) Annual review and assessment of the worlds timber situation. ITTO, Yokohama

Jha S, Dick CW (2010) Native bees mediate long-distance pollen dispersal in a shade coffee landscape mosaic. Proc Natl Acad Sci USA 107(31):13760-13764

Kalinowski ST, Taper ML, Marshall TC (2007) Revising how the computer program CERVUS accommodates genotyping error increases success in paternity assignment. Mol Ecol 16(5): 1099-1106

Kenta T, Isagi Y, Nakagawa M, Yamashita M, Nakashizuka T (2004) Variation in pollen dispersal between years with different pollination conditions in a tropical emergent tree. Mol Ecol 13(11):3575-3584

Kettle CJ, Hollingsworth PM, Jaffré T, Moran B, Ennos RA (2007) Identifying the early genetic consequences of habitat degradation in a highly threatened tropical conifer, Araucaria nemorosa Laubenfels. Mol Ecol 16(17):3581-3591

Kettle CJ, Ennos RA, Jaffré T, Gardner M, Hollingsworth PM (2008) Cryptic genetic bottlenecks during restoration of an endangered tropical conifer. Biol Conserv 141(8):1953-1961

Kettle CJ, Hollingsworth PM, Burslem DFRP, Maycock CR, Khoo E, Ghazoul J (2011a) Determinants of fine-scale spatial genetic 
structure in three co-occurring rain forest canopy trees in Borneo. Perspect Plant Ecol Evol Syst 13(1):47-56

Kettle CJ, Maycock CR, Ghazoul J, Hollingsworth PM, Khoo E, Sukri RS, Burslem DF (2011b) Ecological implications of a flower size/number trade-off in tropical forest trees. PLoS One 6(2):e16111

Kettle CJ, Maycock CR, Burslem D (2012) New directions in dipterocarp biology and conservation: a synthesis. Biotropica 44(5):658-660

Koh LP, Lee TM, Sodhi NS, Ghazoul J (2010) An overhaul of the species-area approach for predicting biodiversity loss: incorporating matrix and edge effects. J Appl Ecol 47(5):1063-1070

Laikre L, Allendorf FW, Aroner LC, Baker CS, Gregovich DP, Hansen MM, Jackson JA, Kendall KC, McKelvey K, Neel MC (2010) Neglect of genetic diversity in implementation of the convention on biological diversity. Conserv Biol 24(1):86-88

Lee S, Wickneswari R, Mahani M, Zakri A (2000) Genetic diversity of a tropical tree species, Shorea leprosula Miq. (Dipterocarpaceae), in Malaysia: implications for conservation of genetic resources and tree improvement. Biotropica 32(2):213-224

Loiselle BA, Sork VL, Nason J, Graham C (1995) Spatial genetic structure of a tropical understory shrub, Psychotria officinalis (rubiaceae). Am J Bot 82(11):1420-1425

Lowe AJ, Boshier D, Ward M, Bacles CFE, Navarro C (2005) Genetic resource impacts of habitat loss and degradation; reconciling empirical evidence and predicted theory for neotropical trees. Heredity 95(4):255-273

Manning AD, Fischer J, Lindenmayer DB (2006) Scattered trees are keystone structures-implications for conservation. Biol Conserv 132(3):311-321

Marshall TC, Slate J, Kruuk LEB, Pemberton JM (1998) Statistical confidence for likelihood-based paternity inference in natural populations. Mol Ecol 7(5):639-655

Murali KS (1997) Patterns of seed size, germination and seed viability of tropical tree species in southern India. Biotropica 29(3): 271-279

Naito Y, Konuma A, Iwata H, Suyama Y, Seiwa K, Okuda T, Lee SL, Muhammad N, Tsumura Y (2005) Selfing and inbreeding depression in seeds and seedlings of Neobalanocarpus heimii (Dipterocarpaceae). J Plant Res 118(6):423-430

Naito Y, Kanzaki M, Iwata H, Obayashi K, Lee S, Muhammad N, Okuda T, Tsumura Y (2008) Density-dependent selfing and its effects on seed performance in a tropical canopy tree species, Shorea acuminata (Dipterocarpaceae). For Ecol Manag 256(3):375-383

Ng KKS, Lee SL, Ueno S (2009) Impact of selective logging on genetic diversity of two tropical tree species with contrasting breeding systems using direct comparison and simulation methods. For Ecol Manag 257(1):107-116
Obayashi K, Tsumura Y, Ihara-Ujino T, Niiyama K, Tanouchi H, Suyama Y, Washitani I, Lee CT, Lee SL, Muhammad N (2002) Genetic diversity and outcrossing rate between undisturbed and selectively logged forests of Shorea curtisii (Dipterocarpaceae) using microsatellite DNA analysis. Int J Plant Sci 163(1):151-158

Ottewell KM, Donnellan SC, Paton DC (2010) Evaluating the demographic, reproductive, and genetic value of eucalypt paddock trees for woodland restoration in agricultural landscapes. Restor Ecol 18:263-272

Pascal JP, Pelissier R (1996) Structure and floristic composition of a tropical evergreen forest in south-west India. J Trop Ecol 12(2):191-214

Peakall R, Smouse PE (2006) GENALEX 6: genetic analysis in Excel. Population genetic software for teaching and research. Mol Ecol Notes 6(1):288-295

Perfecto I, Vandermeer J (2008) Biodiversity conservation in tropical agroecosystems - a new conservation paradigm. Ann NY Acad Sci 1134:173-200

Petit RJ, Hampe A (2006) Some evolutionary consequences of being a tree. Annu Rev Ecol Evol Syst 37(1):187-214

R Development Core Team (2011) R: a language and environment for statistical computing. R Foundation for Statistical Computing, Vienna

Rai S (1990) Restoration of degraded tropical rain forests of Western Ghats. Indian For 116(3):179-188

Sambrook J, Fritsch EF, Maniattis T (1989) Molecular cloning: a laboratory manual, 2nd edn. Cold Spring Harbor Laboratory Press, New York

Sebbenn AM, Carvalho AC, Freitas ML, Moraes SM, Gaino AP, da Silva JM, Jolivet C, Moraes ML (2011) Low levels of realized seed and pollen gene flow and strong spatial genetic structure in a small, isolated and fragmented population of the tropical tree Copaifera langsdorffii Desf. Heredity 106(1):134-145

Smouse PE, Peakall R, Gonzales E (2008) A heterogeneity test for fine-scale genetic structure. Mol Ecol 17(14):3389-3400

Spielman D, Brook BW, Frankham R (2004) Most species are not driven to extinction before genetic factors impact them. Proc Natl Acad Sci USA 101(42):15261-15264

Vekemans X, Hardy OJ (2004) New insights from fine-scale spatial genetic structure analyses in plant populations. Mol Ecol 13(4):921-935

Wells K, Bagchi R (2005) Eat in or take away-seed predation and removal by rats (Muridae) during a fruiting event in a dipterocarp rainforest. Raffles Bull Zool 53:125-130

White GM, Boshier DH, Powell W (2002) Increased pollen flow counteracts fragmentation in a tropical dry forest: an example from Swietenia humilis Zuccarini. Proc Natl Acad Sci USA 99(4):2038-2042 